EESTI NSV TEADUSTE AKADEEMIA TOIMETISED. 19. KÖIDE:

KEEMIA * GEOLOOGIA. 1970, NR. 4

ИЗВЕСТИЯ АКАДЕМИИ НАУК ЭСТОНСКОИ ССР. ТОМ 19

ХИМИЯ * ГЕОЛОГИЯ. 1970, № 4

Т. ПЕХК, Э. ЛИППМАА

\title{
ХИМИЧЕСКИЕ СДВИГИ УГЛЕРОДА-13 ОКСИБЕНЗОЛОВ И ОКСИДИФЕНИЛОВ
}

T. PEHK, E. LIPPMAA. HODROKSOBENSEENIDE JA HODROKSODIFENOOLIDE SOSINIK-13 KEEMILISED NIHKED

T. PEHK, E. LIPPMAA, THE CARBON-13 CHEMICAL SHIFTS OF HYDROXYBENZENES AND. HYDROXYDIPHENYLS

Исследование спектров ЯМР С-13 метоксибензолов показало, что стерические взаимодействия играют существенную роль при экранировании углеродных атомов [1]. Одновременно наблюдается удовлетворительная корреляция между химическими сдвигами углерода и л-электронными плотностями. Можно предположить, что из-за меньшей роли стерических взаимодействий в оксибензолах соблюдается лучшая корреляция между химическими сдвигами и электронными плотностями, чем в метоксибензолах.

Данные о химических сдвигах оксибензолов и оксидифенилов, измеренных по спектрам двойного резонанса и зарегистрированных по ранееописанной методике $\left[{ }^{1,2}\right]$, приведены в таблице. Растворителем для фенолов служил метиловый спирт. Отнесение химических сдвигов в фенолах осуществляется относительно просто, на основании спектров монорезонанса и по сильному селективному влиянию гидроксильной группы на $o-, \mu$ - и $n$-положения ароматического кольца. При отнесении линий оксидифенилов учитывались также сдвиги незамещенного дифенила $\left[{ }^{3}\right]$.

Из изученных соединений только у оксибензола ранее были измереньг химические сдвиги С-13 [4, 5].

Для фенола проведено много различных расчетов электронных плотностей, а полиоксибензолы и оксидифенилы исследованы значительно меньше $\left[{ }^{6,7}\right]$. Так, в работе о корреляции протонных химических сдвигов: оксибензолов с электронными плотностями, рассчитанными по методу Хюккеля (MOX) [6], наилучшая корреляция получена с $h_{\mathrm{OH}}=0,75$ и $k_{\mathrm{CO}}=1,0$. Сравнение углеродных химических сдвигов с этими электронньми плотностями дает удовлетворительную корреляцию отдельно для: замещенных и незамещенных атомов углерода (для 11 незамещенных атомов $r=0,994, s=1,0$ м. д., а для 6 замещенных атомов $r=0,978$ и $s=2,1$ м.д.).

Лучшую корреляцию между химическими сдвигами и электронными плотностями можно было ожидать на основе расчетов по методу: ППП [7]. Однако оба расчетных варианта с учетом б-электронных плотностей не устраняют отдельного группирования замещенных атомовуглерода. Кроме того, наблюдаются сильные отклонения отдельных точек от корреляционных прямых, которые имеют различные наклоны, соот- 
ветствующие изменению химического сдвига $45 \div 140$ м.д. на единицу заряда. Таким образом, усовершенствованные методы расчета не улучшают полученной методом МОХ корреляции.

Для изучения всех измеренных оксибензолов и оксидифенилов, а также для исследования корреляции с электронными плотностями, рассчитанными по $\omega$-способу $[1,9]$, были проведены расчеты электронных плотностей по методу MOX и $\omega$-способу с общепринятыми параметрами $h$ и $k$ для кислорода [9]. По сравнению с метоксибензолами в случае оксибензолов обычно увеличивают величину $h_{0}\left[{ }^{10}\right]$. В данном случае применялись величина $h_{0}=2,1$ (для метоксибензолов $\left.h_{0}=2,0\left[{ }^{1}\right]\right)$ и $k_{\mathrm{CO}}=0,8$. Полученные электронные плотности MOX дают хорошую корреляцию с химическими сдвигами углерода (см. рисунок) по уравнениям:

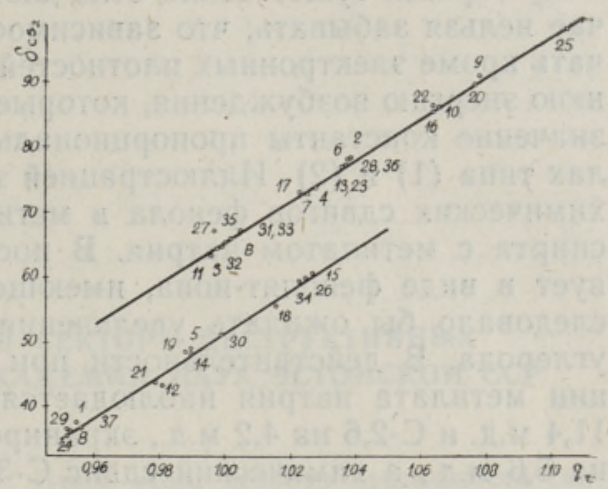

Связь химических сдвигов оксибензолов: и оксидифенилов с электронными плотностями MOX. Номера соответствуют порядковым номерам таблицы. $B$ - бензол.

$$
\begin{aligned}
& \delta_{\mathrm{CS}_{2}}^{\mathrm{CH}}=314,8 q_{r}-249,2 \quad(r=0,997 ; s=0,8 \text { м.д. }), \\
& \delta_{\mathrm{CS}_{2}}^{\mathrm{CO}_{2}}=328,5 q_{r}-277,1 \quad(r=0,996 ; s=0,9 \text { м.д. }) .
\end{aligned}
$$

Электронные плотности, рассчитанные по $\omega$-способу, дают худшую корреляцию.

\begin{tabular}{|c|c|c|c|c|c|c|c|}
\hline № & Вещество & $\begin{array}{l}\text { Углерод- } \\
\text { ный атом }\end{array}$ & $\begin{array}{l}\delta_{\mathrm{Cs}_{2}} \\
\text { м.д. }\end{array}$ & № & Вещество & $\begin{array}{l}\text { Углерод- } \\
\text { ный атом }\end{array}$ & $\begin{array}{l}\delta_{\mathrm{Cs}_{2}} \\
\text { м.д. }\end{array}$ \\
\hline $\begin{array}{r}1 \\
2 \\
3 \\
4 \\
5 \\
6 \\
7 \\
8 \\
9 \\
10 \\
11 \\
12 \\
13 \\
14 \\
15 \\
16 \\
17\end{array}$ & $\begin{array}{l}\text { Пирокатехин } \\
\text { Резорцин }\end{array}$ & $\begin{array}{l}1 \\
2,6 \\
3,5 \\
4 \\
1,2 \\
3,6 \\
4,5 \\
1,3 \\
2 \\
4,6 \\
5 \\
1,4 \\
2,3,5,6 \\
1,3 \\
2 \\
4,6 \\
5\end{array}$ & $\begin{array}{l}37,6 \\
78,5 \\
64,3 \\
73,6 \\
49,1 \\
77,9 \\
72,7 \\
35,5 \\
90,4 \\
85,7 \\
62,8 \\
43,2 \\
76,9 \\
48,0 \\
60,3 \\
85,3 \\
73,4\end{array}$ & $\begin{array}{l}18 \\
\\
19 \\
20 \\
21 \\
22 \\
23 \\
24 \\
25 \\
26 \\
\\
27 \\
28 \\
29 \\
30 \\
31 \\
32 \\
33 \\
34 \\
35 \\
36 \\
37\end{array}$ & $\begin{array}{l}\text { Оксигидро- } \\
\text { хинон } \\
\text { Флороглюцин } \\
\text { 4-Оксидифе- } \\
\text { нил }\end{array}$ & $\begin{array}{l}1 \\
2 \\
3 \\
4 \\
5 \\
6 \\
1,3,5 \\
2,4,6 \\
1 \\
2,6 \\
3.5 \\
4 \\
1^{\prime} \\
2^{\prime}, 6^{\prime} \\
3^{\prime}, 5^{\prime} \\
4^{\prime} \\
\\
1,1^{\prime} \\
2,6,2^{\prime}, 6^{\prime} \\
3,5,3^{\prime}, 5^{\prime} \\
4,4^{\prime}\end{array}$ & $\begin{array}{l}55,7 \\
48,3 \\
89,5 \\
43,6 \\
86,6 \\
77,1 \\
35,4 \\
97,9 \\
\\
60,2 \\
67,1 \\
77,3 \\
36,4 \\
51,8 \\
67,1 \\
64,7 \\
67,1 \\
59,4 \\
65,7 \\
77,2 \\
36,7\end{array}$ \\
\hline
\end{tabular}

Химические сдвиги углерода $\delta \mathrm{cs}_{9}$ оксибензолов и оксидифенилов 
Таким образом, простые расчеты электронных плотностей хорошо коррелируются с углеродными химическими сдвигами. Но коэффициенты пропорциональности, характеризующие изменение экранирования на единицу заряда, существенно отличаются от общепринятых. В данном случае нельзя забывать, что зависимость экранирования ${ }^{13} \mathrm{C}$ должна включать кроме электронных плотностей и другие факторы, в том числе среднюю энергию возбуждения, которые неизбежно должны модифицировать значение константы пропорциональности в крайне упрощенных формулах типа (1) и (2). Иллюстрацией этому положению является сравнение химических сдвигов фенола в метиловом спирте и в смеси метиловогс спирта с метилатом натрия. В последнем растворителе фенол существует в виде фенолят-иона, имеющего отрицательный заряд. Поэтому следовало бы ожидать увеличения суммарного экранирования атомов углерода. В действительности при постепенном увеличении концентрации метилата натрия наблюдается уменьшение экранирования С-1 на 11,4 м.д. и С-2,6 на 4,2 м.д., экранирование С-4 увеличивается всего лишь на 5,6 м.д., а химический сдвиг С-3,5 практически не меняется. В итоге это дает в ионе не увеличение, а уменьшение суммарного экранирования на 14 м.д. С другой стороны, известно, что фенолят-ион имеет две полосы поглощения в электронном спектре при $\lambda=287 m \mu$ и $\lambda=235 m \mu$, а фенол соответственно при $\lambda=270 m \mu$ и $\lambda_{s}=210 m \mu$ [ ${ }^{11}$ ], что неизбежно оказывает некоторое влияние на разницу между экранированием в феноле и в фенолят-ионе и ведет к уменьшению химических сдвигов в ионе.

Метилат натрия не оказывает влияния на химические сдвиги углеродных атомов метоксибензолов. Благодаря этому, путем использования селективных эффектов растворителя можно отнести мало отличающиеся химические сдвиги одной мультиплетности в метоксифенолах (гваякол и др.).

\section{ЛИТЕРАТ У РА}

1. Пехк Т., Липпм а а Э., Изв. АН ЭССР, Хим. Геол., 17, 195 (1968).

2. Л иппм а а Э.. П Ехк Т.. П а с т Я.. Изв. АН ЭССР, Физ. Матем., 16, 345 (1967).

3. A 1 ge r T. D., G r a n t D. M., P a u 1 E. G., J. Am. Chem. Soc., 88, 5397 (1966).

4. La a terbur P. C., J. Am. Chem. Soc., 83, 1846 (1961).

5. Ma ciel G. E., J a me s R. V., J. Am. Chem. Soc., 86, 3893 (1964).

6. S c hug J. C., D e c k J. C., J. Chem. Phys., 37, 2618 (1962).

7. Pukanic G. W., Forshey D. R., Wegener B. J. D., Greenshields J. B., Theor. Chim. Acta, 9, 38 (1967).

8. Ettinger R., Tetrahedron, 20, 1579 (1964).

9. С трей твизер Э., Теория молекулярных орбит, Мир, 1965.

10. Forsen S., A kerm a r k B., A 1 m T., Acta Chem. Scand., 18, 313 (1964).

11. Doub L., V a nde n belt J. M., J. Am. Chem. Soc., 69, 2714 (1947).

Ннститут кибернетики Академии наук Эстонской ССР
Поступила в редакщию 25/III 1970 